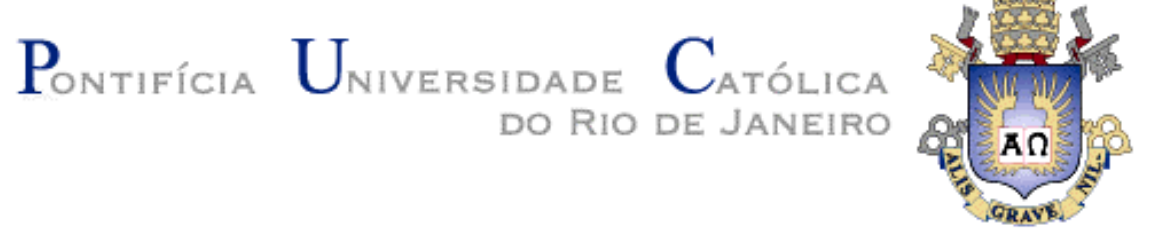

Marco Antonio da Silva Ramidan

\author{
Estudo de UM Processo de \\ VOÇOROCAMENTO PRÓXIMO A UHE DE \\ ITUMBIARA - GO
}

Dissertação de Mestrado

Dissertação apresentada ao Departamento de Engenharia Civil da PUC-Rio como parte dos requisitos para obtenção do título de Mestre em Ciências de Engenharia Civil: Geotecnia

Orientadores: $\operatorname{Prof}^{\circ}$. Tácio Mauro P. Campos Prof $^{\circ}$. Franklin S. Antunes

Rio de Janeiro

Setembro de 2003 


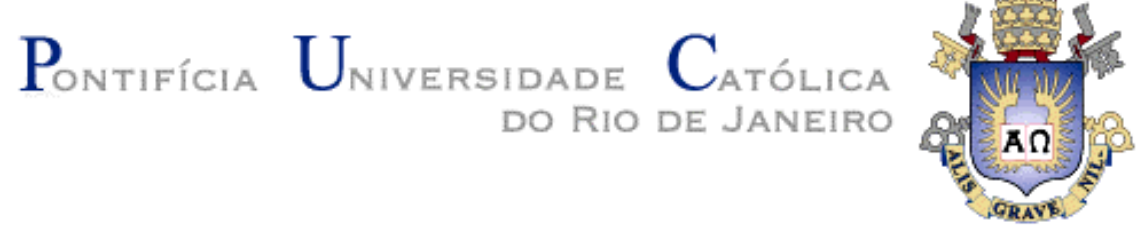

Marco Antonio da Silva Ramidan

\title{
Estudo de um processo de voçorocamento próximo a UHE de Itumbiara - GO
}

Dissertação apresentada como requisito parcial para obtenção do título de Mestre pelo Programa de PósGraduação em Engenharia civil do Departamento de Engenharia Civil do Centro Técnico Científico da PUC-Rio. Aprovada pela Comissão Examinadora abaixo assinada.

\author{
Prof. Tácio Mauro P. de Campos \\ Presidente/ Orientador \\ Departamento de Engenharia Civil - PUC - Rio \\ Prof. Franklin dos Santos Antunes \\ Co-Orientador \\ Departamento de Engenharia Civil - PUC - Rio \\ Prof. Eurípides do A. Vargas Jr. \\ Departamento de Engenharia Civil - PUC - Rio \\ Eng. Celso José Pires Filho \\ FURNAS Centrais Elétricas S.A. \\ Prof. Nelson Ferreira Fernandes \\ IG/UFRJ \\ Prof. Ney Augusto Dumont \\ Coordenador Setorial \\ do Centro Técnico Científico - PUC - Rio
}

Rio de Janeiro, 19 de Setembro de 2003 
Todos os direitos reservados. É proibida a reprodução total ou parcial do trabalho sem autorização do autor, do orientador e da universidade.

\section{Marco Antonio da S. Ramidan}

Engenheiro Civil, pertencente ao quadro de Furnas Centrais Elétricas S. A, SE.T / DEC.T. Ingressou no curso de Mestrado em Engenharia Civil, na área de Geotecnia no ano de 2000, atualmente atuando na área de Geotecnia, na Divisão de Geotecnia e Segurança de Barragem - DGSB.T. Desenvolveu pesquisa sobre o estudo dos processos erosivos em ocorrência na região referente a uma área de empréstimo, situada a jusante da barragem de terra, ombreira direita, da UHE de Itumbiara - GO. Pretende-se, a partir do levantamento de informações Geológico-Geotécnicas; Climáticas; Instrumentação de campo e execução de Ensaios de Laboratório e Campo, definir o mecanismo de erosão atuante e propor alternativas de Solução para o problema.

Ficha Catalográfica

Ramidan, Marco Antonio da Silva

Estudo de um Processo de Voçorocamento próximo a UHE de Itumbiara - GO/ Marco Antonio S. Ramidan; orientadores: Tácio Mauro P. Campos; co-orientador: Franklin S. Antunes - Rio de Janeiro: PUC, Departamento de Engenharia Civil, 2003.

v.1, 242 f.:il. ; $29,7 \mathrm{~cm}$

1. Dissertação (mestrado) - Pontifícia Universidade Católica do Rio de Janeiro, Departamento de Engenharia Civil.

Inclui referências bibliográficas

1. Hidrelétrica; 2. Erosão; 3. Voçoroca; 4. Geológicogeotécnico; 5. Ensaios. I. Ramidan, M. A. S. (Marco Antonio da Silva Ramidan). II. Pontifícia Universidade Católica do Rio de Janeiro. Departamento de Engenharia Civil. III. Título 
In Memorian

Aos meus queridos e saudosos pais, Omar e Raymunda, pelo grande exemplo de vida e incentivo ao desenvolvimento intelectual $\mathrm{e}$ científico. 
Dedico a minha querida esposa Eliane e aos meus filhos Leonardo e Caroline a compreensão pelos momentos em que me fiz ausente para a elaboração desta dissertação e por sempre me apoiarem e incentivarem, em todos esses anos de estudo. 


\section{Agradecimentos}

Aos meus irmãos, irmãs, sobrinhos e sobrinhas que sempre torceram pelo meu sucesso.

Aos professores Franklin dos Santos Antunes e Tácio Mauro Pereira de Campos, pela orientação, dedicação e companheirismo ao longo do curso.

Aos demais professores do Departamento de Engenharia Civil da PUC-Rio, em especial aos professores Eurípedes do A. Vargas Jr., Celso Romanel, Alberto Sayão, Sérgio Fontoura, José Araruna e Cláudio Amaral, pelo incentivo, companheirismo e conhecimentos obtidos ao longo do curso de mestrado.

Aos meus amigos e colegas da PUC-Rio dos cursos de mestrado e doutorado, que sempre me ajudaram de certa forma e que me incentivaram durante todos esses anos de estudo e pesquisa. Em especial aos colegas: Rodrigo Spangnolo, Fávio Alchaar, Carlos Caetano, Ewerton Pimentel, Carlos Ataliba, Ciro Portela, Ricardo Cuentas, Javier Perez e Jorge L. Cárdenas.

Aos funcionários do DEC, PUC-Rio, pelo profissionalismo e dedicação, em especial a Ana Roxo por quem tenho um imenso carinho e admiração.

Aos funcionários do Laboratório de Mecânica dos Solos, PUC-Rio, pela ajuda na execução dos ensaios, indispensável ao desenvolvimento deste trabalho, em especial ao Willian e Amauri.

Ao Laboratório de Difratometria de Raios-X, do DCMM da PUC-Rio, em especial ao Ronaldo pela colaboração neste ensaio.

À empresa Furnas Centrais Elétricas S.A., grande incentivadora e inovadora na área de pesquisa e desenvolvimento Técnico Científico, sem a qual não seria possível o 
desenvolvimento deste estudo, em especial à Superintendência de Engenharia (SE. T) e Superintendência de Geração (SG.T), aos Departamentos de Patrimônio Imobiliário (DPI.T), Departamento de Engenharia Civil (DEC.T), Departamento de Construção de Geração Corumbá (DGB.T), Departamento de Produção Goiás (DRG.O) e ao Departamento de Apoio e Controle Técnico (DCT.T).

Aos colegas de Furnas, Eng ${ }^{\circ}$ Antônio de Pádua (SG. T); Eng ${ }^{\circ}$ Walton Pacelli, Eng ${ }^{\circ}$ Cláudia de Castro e Geólogo Pedro de Moura (DCT. T); Eng ${ }^{\circ}$ Hélio Goulart, Eng ${ }^{\circ}$ Ademar B. Filho, Eng ${ }^{\circ}$ Cláudio Motta, Des. Proj. Danilo Reis, Engo Étore F. de Faria (DEC. T), Eng ${ }^{0} J_{0}$ Ré Reinaldo, Des. Proj. Maria da Conceição (DPI. T), pelo incentivo e apoio que me deram ao longo do desenvolvimento deste curso.

Aos Eng ${ }^{\text {os }}$ José Gilvomar e Manoel Martins, pela solidariedade com o desenvolvimento da causa geotécnica.

Em especial, ao Eng ${ }^{\circ}$ Celso Pires (DEC. T) coordenador do convênio entre Furnas e PUC, meu amigo e grande incentivador que sempre se mostrou solícito e atuante, quando solicitado a intervir em prol do bom desempenho desse programa de trabalho e ao Eng $^{\circ}$ Wanderson Silvério (DCT. T), pelo apoio na realização dos ensaios no laboratório de solos de Furnas-GO. 


\section{Resumo}

Ramidan, Marco Antonio da Silva; Campos, Tácio Mauro Pereira; Antunes, Franklin dos Santos. Estudo de um Processo de Voçorocamento próximo a UHE de Itumbiara - GO. Rio de Janeiro, 2003, 242p. Dissertação de Mestrado - Departamento de Engenharia Civil, Pontifícia Universidade Católica do Rio de Janeiro.

Esta dissertação, desenvolvida dentro do contexto do projeto PRONEX do Centro Geotécnico de Meio Ambiente da PUC-Rio e através de um convênio com FURNAS - PUC-Rio, apresenta uma contribuição quanto à identificação e compreensão dos mecanismos envolvidos em processos de erosão, considerando seus aspectos geológico-geotécnicos bem como medidas preventivas de reparo no caso da formação de uma voçoroca específica. A evolução do processo erosivo estudado tem suas origens na remoção mecânica de uma camada com cerca de cinco metros de solo argiloso de uma área explorada na época da construção de uma barragem de terra homogênea pertencente ao complexo Hidrelétrico de Itumbiara. Os principais aspectos da área estudada, tais como sua localização, condições climáticas e tipos de solo e vegetação foram considerados no desenvolvimento do trabalho, além de aspectos geológicos regionais e características geológico-geotécnicas da área afetada pelos processos de erosão. Tomando como base o perfil de intemperismo identificado pela inspeção das paredes da formação da voçoroca, bem como amostras de furos de sondagens SPT (ensaio de penetração normal), quatro tipos de camadas de solo foram tomados como representantes das condições do local. Objetivando-se a identificação, classificação e definição do potencial de erosão de tais materiais, espécies de amostras indeformadas de bloco (bem como as amolgadas) foram submetidas a investigações laboratoriais abrangendo: ensaio convencional de caracterização de solo; ensaio de caracterização MCT (mini-MCV); Crumb Test; ensaio de Desagregação; Pinhole Test; e Inderbitzen; ensaios de permeabilidade (também desenvolvidos em campo); análise química da água intersticial; análise mineralógica (difração de raios-X); ensaio de Resistência a Tração (sob condições de saturações 
diferentes) e ensaio de papel filtro (para definição das curvas características da umidade). Baseado em testes de laboratório, observações e dados de pesquisas de campo advindos de um monitoramento de poro-pressão (através de piezômetros instalados no local), mecanismos de erosão que possam predominar na área foram definidos como: micro-ravinas, ravinas e voçorocas, dentre outros. Também, ao final do trabalho, são apresentadas sugestões para remediação do local, considerando-se medidas corretivas usadas dentro do contexto da prática geotécnica convencional, e uma metodologia a ser seguida em investigações futuras relacionadas à caracterização do local e desenvolvimento de processos de erosão.

\section{Palavras-Chave}

Complexo Hidrelétrico de Itumbiara; Erosão; Voçoroca; GeológicoGeotécnico; Ensaios Geotécnicos. 


\section{Abstract}

Ramidan, Marco Antonio da Silva; Campos, Tácio Mauro Pereira (Advisor); Antunes, Franklin dos Santos (Advisor). The Gully Process Study next to the Itumbiara Hydroelectric Complex - GO. Rio de Janeiro, 2003, 242p. M.Sc. Dissertation - Departamento de Engenharia Civil, Pontifícia Universidade Católica do Rio de Janeiro.

This dissertation, developed within the context of the PRONEX Project of the Environmental Geotechnical Center of PUC-Rio and through a FURNAS-PUC-Rio Convenium, presents a contribution towards the identification and comprehension of mechanisms involved in erosion processes, considering its geological and geotechnical aspects as well as preventive repairing measures in the case of a specific gully formation. The evolution of the studied erosive process has its origin in the mechanical removal of some five meters of a clayey soil layer from a borrow area exploited at the time of the construction of an homogeneous embankment dam belonging to the Itumbiara Hydroelectric Complex. The main aspects of the studied area, such as its location, climatic conditions and soil and vegetation types were considered in the development of the work, besides regional geological aspects and geological-geotechnical features of the area affected by the erosion processes. Taking as a basis the unsaturated weathering profile identified by inspection of the walls of the gully formation, as well as of samples from SPT (standard penetration test) boreholes, four types of soil 'layers' were taken as representative of site conditions. Aiming the identification, classification and definition of the erodibility potential of such materials, specimens from undisturbed block samples (as well as remolded ones) were submitted to laboratory investigations comprising: conventional soil characterization tests; MCT characterization test (mini-MCV); crumb test; desegregation test; pinhole test; Inderbitzen test, permeability tests (also performed in the field); chemical analysis (both soil and voids -water); mineralogical analysis ( $\mathrm{X}$ rays diffraction); tensile strength test (under different saturation conditions) and filter paper test (for definition of soil-moisture characteristic curves). Based on the results 
of the laboratory tests, field observations and data from pore-pressure monitoring (through piezometers installed in the site), erosion mechanisms that may prevail in the area were defined as micro-rills, rill, gully and others. Also, at the end of the work, are presented suggestions for remediation of the site, considering corrective measures used within the context of conventional geotechnical practice, and a methodology to be followed in further investigations related to the characterization of the site and development of erosion processes.

\section{Keywords}

Itumbiara Hydroelectric Complex; Erosion; Gully; Geological-Geotechnical; Geotechnical Tests. 


\section{Sumário}

1 Introdução 26

$\begin{array}{lll}1.1 \text { Objetivo } & 27\end{array}$

1.1.1 Geral 27

1.1.2 Específico 27

1.2 Escopo do Trabalho 28

2 Revisão Bibliográfica $\quad 29$

$\begin{array}{lll}2.1 \text { Considerações Iniciais } & 29\end{array}$

2.2 Formações Superficiais e Desencadeamento dos Processos $\begin{array}{ll}\text { Erosivos } & 29\end{array}$

2.3 Processos Determinantes na Erosão dos Solos 34

2.3.1 Processos Relacionados às Formas de Erosão Hídrica 36

2.3.2 Processos Relacionados a Precipitações Pluviométricas 38

2.3.3. Processos Relacionados à Erosão Eólica 42

2.3.4 Processos Erosivos Devido à Geometria de Encostas 43

2.3.5 Processos Erosivos por Formação de Ravinas e Voçorocas 44

2.3.6 Aspectos Geológico-Geotécnicos dos Solos 47

2.3.7 Quantificação de Perda de Solo por Erosão Laminar 54

3 Aspectos Gerais da Área Estudada 58

3.1 Localização 58

3.2 Condições Climáticas 61

3.3 Tipo de Solo 63

3.4 Tipo de Vegetação 63

3.5 Aspecto Geológico - Geotécnicos da Região 64

4 Metodologia adotada na Avaliação da Erodibilidade 69

$\begin{array}{ll}\text { 4.1 Trabalhos Desenvolvidos no Campo } & 69\end{array}$ 
4.2 Aspecto Geológico - Geotécnicos Local 75

4.3 Hidrologia Local 79

5 Descrição dos Ensaios e Apresentação dos Resultados 86

5.1 Ensaios de Campo 87

5.1.1 Ensaio Penetrométrico (SPT) 87

5.1.2 Ensaio com o Permeâmetro de Guelph 87

5.2 Ensaios de Laboratórios $\quad 90$

5.3. Ensaios Convencionais de Caracterização 92

5.3.1. Metodologia Adotada 92

5.3.2. Apresentação e Análise dos Resultados 94

5.3.2.1. Análise Granulométrica 95

5.3.2.2. Limite de Atterberg 99

5.3.2.3. Umidade Natural e Umidade Higroscópica 101

5.3.2.4. Peso Específico 103

5.3.2.5. Índice de Vazios, Porosidade e Grau de Saturação 104

5.3.2.6. Índice de Atividade 106

5.3.3. Correlação entre as propriedades físicas 107

5.4. Ensaios de Erodibilidade 111

5.4.1 Crumb Test 111

5.4.2. Desagregação 117

5.4.3. Ensaio Pinhole Test (Furo de Agulha) 127

5.4.4 Inderbitzen 145

5.5 Ensaios Especiais 155

5.5.1 Análise Química do Solo e da Água Intersticial 155

5.5.2 Caracterização Mineralógica (Difração de Raios-X) 158

5.5.3 Ensaio de Caracterização MCT (mini-MCV) 167

5.5.4 Ensaio de Sucção (Curva Característica) 181

5.5.5 Ensaio de Resistência a Tração - Método Brasileiro 198

6 Discussão dos Resultados 203 
7 Conclusões e Sugestões

Referências Bibliográficas

Anexo 


\section{Lista de tabelas}

Tabela 5.1 - Resumo das Principais propriedades Físicas do Solo

Tabela 5.2 - Critério de classificação direta dos solos estudados quanto ao grau de erodibilidade, proposto por Santos e Castro (1967)

Tabela 5.3 - Limites de Atterberg para argilominerais (modificado por Mitchell, 1993)

Tabela 5.4 - Massa Específica dos Minerais Identificados (modificado - Deer et al, 1981)

Tabela 5.5 - Guia de interpretação proposta por Sherard et al (1976) 112

Tabela 5.6 - Resultado do ensaio Crumb Test

Tabela 5.7 - Resumo dos resultados do ensaio sedimentométrico comparativo $(0,002-0,05 \mathrm{~mm})$

Tabela 5.8 - Resumo dos critérios interpretativos do Ensaio Pinhole Test (Furo de Agulha) ASTM. D 4647-(93) adaptado a NBR 14114-98 sob forma de texto

Tabela 5.9 - Condições de moldagem do Corpo de Prova para o ensaio (SC)

Tabela 5.10 - Condições de moldagem do Corpo de Prova para o ensaio (SRM)

Tabela 5.11 - Condições de moldagem do Corpo de Prova para o ensaio (SRJ-A)

Tabela 5.12 - Condições de moldagem do Corpo de Prova para o ensaio (SRJ-B)

Tabela 5.13 - Quadro resumo da quantidade de perda do Solo Coluvionar (SC)

Tabela 5.14 - Caracterização Química do Solo

Tabela 5.15 - Análise Química da Água 156

Tabela 5.16 - Análise Mineralógica pela difração de Raios-X 160

Tabela 5.17 - Quadro característico de solos dos grupos MCT, quanto à erodibilidade hídrica e propriedades de interesse à sua previsão (condições típicas do Estado de São Paulo) - modificado por Nogami e Villibor, 1995

Tabela 5.18 - Valores para classificação mini-MCV do Solo Coluvionar 174 Tabela 5.19 - Valores para classificação mini-MCV do Solo Maduro 176 
Tabela 5.20 - Valores para classificação mini-MCV do Solo Residual Jovem A

Tabela 5.21 - Valores para classificação mini-MCV do Solo Residual Jovem

$\mathrm{B}$

Tabela 5.22 - Célula de placa cerâmica e suprimento de gás utilizado no ensaio

Tabela 5.23 - Valores obtidos pelo método do Papel Filtro

Tabela 5.24 - Valores obtidos pelo método da Panela de Richards

Tabela 5.25 - Amostra de solo na umidade natural 201

Tabela 5.26 - Amostra de solo seca ao ar 201

Tabela 9.1 - Quadro resumo da quantidade de perda de solo laterítico (SL)

Tabela 9.2 - Quadro resumo da quantidade de perda de solo (SRJ-B) 240

Tabela 9.3 - Quadro resumo da quantidade de perda de solo (SRJA) 241

Tabela 9.4 - Quadro resumo de perda de solo (SRM) 


\section{Lista de figuras}

Figura 3.1 - Mapa de Localização da UHE de Itumbiara - GO / Geomapas Produções Cartográficas Ltda (1994) - Escala 1:400. 000

Figura 3.2 - Planta Geral com Representação da Hidrogeologia Local $\quad 60$

Figura 3.3 - Precipitações pluviométric as anuais (Jan/1980-Jun/2003) 62

Figura 3.4 - Precipitações pluviométricas mensais (Jan/80 - Jun/03) 62

Figura 3.5 - Precipitações pluviométricas mensais (Jan2003-Jun/2003) 62

Figura 3.6 - Mapa Geológico Regional - Fonte: AGIM (Agência Goiana de Desenvolvimento Industrial e Mineral). Mapa Geológico e de Recursos Minerais.

Figura 3.7 - Mapa Geológico Local

Figura 3.9 - Seção Longitudinal no eixo da barragem - Fonte: Relatórios de Furnas Centrais Elétricas S.A. Simpósio sobre a Geotecnia da Bacia do Alto Paraná (setembro de 1983) - modificado pelo autor, 2003.

Figura 4.1 - Coleta de Água

Figura 4.2 - Vista aérea com destaque para Erosão 1

Figura 4.3 - Planta da Erosão 1

Figura 4.4 - Perfil Representativo dos Taludes

Figura 4.5 - Local de retirada de blocos (SC - Solo Coluvionar ; SRM - Solo Residual Maduro ; SRJ-A - Solo Residual Jovem A ; SRJ-B - Solo Residual Jovem B)

Figura 4.6 - Tipos de Solos

Figura 4.7 - Perfil Geológico-Geotécnico (Seção Longitudinal AB - Figura 3.2)

Figura 4.8 - Alcovas de regressão e queda de bloco

Figura 4.9 - Trinca superficial (vista lateral e superior)

Figura 4.10 - Fraturas de alívio sub-horizontais / verticais a sub-verticais (Parede esquerda da Erosão I)

Figura 4.11 - Leituras Piezômetros e medidores de níveis d'água recentemente instalados

Figura 4.12 - Leituras dos Piezômetros e medidores de níveis d'água existentes ao longo da ombreira direita da barragem

Figura 4.13 - Leituras da precipitação pluviométrica versus elevação do reservatório 
Figura 4.14 - Modelo dinâmico da evolução das voçorocas

Figura 4.15 - Modelo representativo do comportamento de fluxo no processo erosivo do solo estudado (estágio I)

Figura 4.16 - Modelo representativo do comportamento de fluxo no processo erosivo do solo estudado (estágio II)

Figura 4.17 - Modelo representativo dos processos erosivos resultantes da incidência de fluxo sobre o solo estudado (estágio I)

Figura 4.18 - Modelo representativo dos processos erosivos resultantes da incidência de fluxo sobre o solo estudado (estágio II)

Figura 5.1 - Ensaio com Permeâmetro de Guelph

Figura 5.2 - Valores de $\mathrm{K}(\mathrm{cm} / \mathrm{s}), \mathrm{K}_{\mathrm{s}}(\mathrm{cm} / \mathrm{s})$ e $\mathrm{F}_{\mathrm{m}}(\mathrm{cm} / \mathrm{s})$

Figura 5.3 - Curva Granulométrica por peneiramento e sedimentação 96

Figura 5.4 - Variação das Frações Silte e Argila por sedimentação 98

Figura 5.5 - Variação das Frações Pedregulho + Areia 98

Figura 5.6 - Variação dos Limites de Atterberg

Figura 5.7 - Variação dos teores de Umidade Natural $\left(W_{\text {nat }}\right)$ e Umidade Higroscópica $\left(\mathrm{W}_{\mathrm{h}}\right)$

Figura 5.8 - Variação do Peso específico aparente seco $\left(\gamma_{d}\right)$ com o peso específico natural $\left(\gamma_{\text {nat }}\right)$ e o Peso específico dos sólidos $\left(\gamma_{s}\right)$

Figura 5.9 - Variação do Índice de Vazios (e), Porosidade (n) e do Grau de Saturação (S)

Figura 5.10 - Variação do Índice de Atividade

Figura 5.11 - Análise da unidade higroscópica $\left(W_{h}\right)$ em função do Índice de Plasticidade (b)

Figura 5.12 - Índice de Plasticidade, Umidade higroscópica versus o porcentual de argila.

Figura 5.13 - limite de Atterberg e Umidade higroscópica versus Porcentual de argila e silte

Figura 5.14 - Curvas representativos do Ensaio Sedimentométrico

Comparativo

Figura 5.15 - Amostras colocadas sobre Pedra Porosa, Ensaio de Imersão Progressiva (até a base $-30 \mathrm{~min}$ )

Figura 5.16 - Amostras colocadas sobre Pedra Porosa, Ensaio de Imersão Progressiva (até a 1/3 H - 45 min)

Figura 5.17 - Amostras colocadas sobre Pedra Porosa, Ensaio de Imersão Progressiva (até a 2/3 H -60 min) 
Figura 5.18 - Amostras colocadas sobre Pedra Porosa, Ensaio de Imersão Total (período de 24 horas)

Figura 5.19 - Amostras colocadas sobre Pedra Porosa, Ensaio de Imersão

Total (logo após a inundação)

Figura 5.20 - Amostras colocadas sobre Pedra Porosa, Ensaio de Imersão

Total (após $15 \mathrm{~min}$ )

Figura 5.21 - Amostras colocadas sobre Pedra Porosa, Ensaio de Imersão Total (após $24 \mathrm{~h}$ )

Figura 5.22 - Modelo Esquemático do Ensaio de Pinhole Test

Figura 5.23 - Resultados do Ensaio, tempo e carga hidráulica em função da vazão. (Solo Coluvionar)

Figura 5.24 - Fotos Representativas da amostra de Solo Coluvionar após o ensaio

Figura 5.25 - Resultados do Ensaio, tempo e carga hidráulica em função da vazão (SRM)

Figura 5.26 - Fotos Representativas da amostra de Solo Residual Maduro após o ensaio

Figura 5.27 - Resultados do Ensaio, tempo e carga hidráulica em função da vazão (SRJA)

Figura 5.28 - Fotos Representativas da amostra de Solo Residual Jovem A após o ens aio

Figura 5.29 - Resultados do Ensaio, tempo e carga hidráulica em função da vazão (SRJ-B)

Figura 5.30 - Fotos Representativas da amostra de Solo Residual Jovem B após o ensaio

Figura 5.31 - Resultados do Ensaio, tempo e carga hidráulica em função da vazão (SC)

Figura 5.32 - Resultados do Ensaio, tempo e carga hidráulica em função da vazão (SRM)

Figura 5.33 - Resultados do Ensaio, tempo e carga hidráulica em função da vazão (SRJ-A)

Figura 5.34 - Resultados do Ensaio, tempo e carga hidráulica em função da vazão (SRJ-B) 144

Figura 5.35 - Ensaio de Inderbitzen em andamento 146

Figura 5.36 - Resultado da perda de solo total das amostras 149

Figura 5.37 - Resultado da perda de Solo Coluvionar 151

Figura 5.38 - Resultado da perda de Solo Laterítico 152 
Figura 5.39 - Resultado de perda de solo (SRJ-B) 153

Figura 5.40 - Resultado da perda de solo (SRJ-A) 154

Figura 5.41 - Resultado da perda de solo (SRM) 155

Figura 5.42 - Difratogramas de Raios-X (SNE e SC) 162

Figura 5.43 - Difratogramas de Raios-X (SE e SRM) 164

Figura 5.44 - Difratogramas de Raios-X (SRJ-A e SRJ-B) 166

Figura 5.45 - Aparelho com Ensaio de Classificação MCT em andamento e $\begin{array}{ll}\text { esquema representativo } & 168\end{array}$

Figura 5.46 - Exemplo de curvas de deformabilidade - MCV 169

Figura 5.47 - Exemplo de Curva para determinação de c' 170

Figura 5.48 - Exemplo de Curva de Compactação para determinação de d'

Figura 5.49 - Representação Esquemática do Ensaio de Perda de solo por Imersão

Figura 5.50 - Ábaco classificatório dos solos pela metodologia MCT 173

Figura 5.51 - Gráficos e representação esquemática do ensaio mini -MCV (SC)

Figura 5.52 - Gráficos e representação esquemática do ensaio mini -MCV (SRM)

Figura 5.53 - Gráficos e representação esquemática do ensaio mini -MCV (SRJ-A)

Figura 5.54 - Gráficos e representação esquemática do ensaio mini -MCV (SRJ-B)

Figura 5.55 - Extração da amostra de solo com anel de metal 183

Figura 5.56 - Amostras de solos envolvidos com filmes plásticos 185

Figura 5.57 - Balança para pesagem de papel filtro 186

Figura 5.58 - Curvas Características pelo método do Papel Filtro 186

Figura 5.59 - Câmara de Pressão de Richards

Figura 5.60-Saturação de amostras de solos por capilaridade sobre placa cerâmica

Figura 5.61 - Expansão da amostra de Solo Residual Maduro (SRM) 189

Figura 5.62 - Saturação de amostras de solo por capilaridade 189

Figura 5.63 - Curva de sucção pelo método de Panela de Richards 190

Figura 5.64 - Curvas características de sucção versus umidade, obtidas segundo os métodos de Papel Filtro e da Panela de Richards 
Figura 5.65 - Ensaio de tração (equipamento e ensaio em andamento) 198 Figura 5.66 - Soluções teóricas das tensões ao longo do diâmetro vertical de uma amostra de solo submetida a compressão diametral

Figura 5.67 - Representação gráfica das amostras natural e seca ao ar 202 


\section{Lista de abreviaturas e símbolos}

S: somatório

$\circ$ : graus

\#: peneira

$\%$ : porcentagem

A: Índice que representa a parte de solo por unidade de área

a: fator de redução

ABNT: Associação Brasileira de Normas Técnicas

AGIM: Agência Goiana de Desenvolvimento Industrial e Mineral

Al: alumínio

$\mathrm{Al}^{3+}$ : cátion de alumínio

C: argilas

C: Índice relativo ao fator referente ao uso e manejo do solo

Ca: cálcio

cm: centímetro

$\mathrm{cm}^{2}$ : centímetro quadrado

$\mathrm{cm}^{3}$ : centímetro cúbico

$\mathrm{cm}^{3} / \mathrm{s}$ : centímetro cúbico por segundo

CNPS: Centro Nacional de Pesquisa de Solos

$\mathrm{Cu}$ : c oeficiente de não uniformidade dos solos

D: diâmetro

DAEE: Departamento de Águas e Energia Elétrica

DATUM-SAD-69: Sputh American DATUM-69

EMBRAPA: Empresa Brasileira de Pesquisas Agrárias

$E$ : Energia cinética total para um dado evento chuvoso

EPG: ensaio com permeâmetro de Guelph

e : índice de vazios

$\mathrm{e}_{\mathrm{o}}$ : índice de vazios inicial

Fe: ferro 
G: cascalho

g: grama

GO: Goiás

GPS: Global Positioning System ou NAVSTAR-GPS (Navigation Satellite with time and ranging)

h: hora

h०T: umidade ótica

Hc: Teor de umidade de compactação

$\mathrm{H}_{2} \mathrm{O}$ : água

I: Equivale a precipitação pluviométrica máxima durante 30 minutos

la: Î́ndice de atividade das argilas

$\mathrm{K}$ : potássio

$\mathrm{K}$ : Índice relativo a erodibilidade do solo

$\mathrm{K}$ : permeabilidade

$\mathrm{K}_{\mathrm{fs}}$ : condutividade hidráulica saturada de campo

$\mathrm{K}_{\mathrm{m} \text { : }}$ permeabilidade média

$\mathrm{L}$ : Índice relativo ao comprimento da encosta

Li: lítio

LA': Solo laterítico arenoso

LG': Solo laterítico argiloso

M: siltes

m: metro

Marégrafo: Referencial altímétrico, coincidente com a superfície equipotencial que contém o nível médio do mar

MCT: Miniatura Compactada Tropical

Mini-MCV: Moisture Condition Value

Md: Massa seca da parte desprendida

Ms: Massa seca em estufa

Mu: Massa úmida do corpo de prova

min: minuto

ml: mililitro 


\author{
MG: Minas Gerais \\ Mg: magnésio \\ $\mathrm{m} / \mathrm{s}$ : metro por segundo \\ $\mathrm{mm}$ : milímetro \\ $\mathrm{mm} / \mathrm{h}$ : milímetro por hora \\ n: Porosidade \\ $\mathrm{Na}$ : sódio \\ $\mathrm{NaOH}$ : hidróxido de sódio \\ O: solos orgânicos \\ $\mathrm{P}$ : Índice relativo a prática conservacionista adotada \\ Pd: Grau de dispersão \\ PG: permeâmetro de Guelph \\ Pi: Perda de solo por imersão \\ $\mathrm{pH}$ : potencial de hidrogenização \\ PZ: piezômetro \\ $\mathrm{R}$ : Índice relativo a erodibilidade da chuva e da enxurrada \\ S: areias \\ S: Grau da saturação \\ S: Índice relativo a declividade da encosta \\ SC: Solo coluvionar \\ SCS: Ensaio Sedimentométrico comparativo \\ SE: Solo Erodido
}

Seg: segundo

SNE: Solo Não Erodido

SRJ-A: Solo Residual Jovem A

SRJ-B: Solo Residual Jovem B

SRM: Solo Residual Maduro

SPT: Standard Penetration Test (Sondagem a percussão)

UHE: Usina Hidrelétrica

USLE: Universal Soil Loss Equation (Equação Universal de Perdas de Solos)

UTM: Universal Transverso de Mercator 
w: umidade do solo

WEPP: Water Erosion Predict Project - Projeto de Previsão de Erosão Hídrica

$\mathrm{W}_{\mathrm{L}}$ : Limite de liquidez

$w_{\text {na t: }}$ Umidade natural do solo

$\mathrm{w}_{\mathrm{p}}$ : Índice de plasticidade

$\mathrm{w}_{\mathrm{h}}$ : Umidade Higroscópica

$\gamma_{s}$ :Peso específico real dos grãos

$\gamma_{\text {nat }}$ Peso específico natural

$\gamma_{d}:$ Peso específico seco

$\mu_{\mathrm{m}}$ : mícron (= 0,001 milímetro)

$F_{m}$ : potencial de fluxo mátrico 